\title{
Radiation therapy is an important factor to improve survival in pediatric patients with head and neck rhabdomyosarcoma by enhancing local control: a historical cohort study from a single center
}

\author{
Yuan\ Wen, Dongsheng Huang* (D), Weiling Zhang, Yi Zhang, Huimin Hu and Jing Li
}

\begin{abstract}
Background: The purpose of this study is to analyze the influence of radiation therapy on survival in a historical cohort of 56 pediatric patients with head and neck rhabdomyosarcoma.

Methods: A historical cohort of 56 pediatric patients with head and neck rhabdomyosarcoma from June 1st, 2013 to June 30th, 2019 was chosen. Clinical data and follow up results were collected including all diagnosis, treatment and prognosis information. Overall survival (OS) and event free survival (EFS) as time-to-event distributions were estimated with Kaplan-Meier method, and univariate analysis was performed with log rank test to detect differences between groups. Multivariate analysis was performed to explore the risk factors for survival with Cox proportional hazard model.

Results: The media follow up time of all 56 patients was 31.8 months (range 3.5-74.6 months). There were 26 events during follow up, including 14 disease progressions and 12 relapses. The estimated 5 -year OS of all patients was $69.9 \%$, and the estimated 5 -year EFS was $48.8 \%$. Patients with radiation therapy as a component of the initial treatment plan had better 5-year OS and EFS compared with those without radiation therapy (OS 80.3\% vs. 49.7\%, $p=0.003$ and EFS $63.9 \%$ vs. $21.9 \%, p<0.001$ ). In patients with events, those who received salvage radiation therapy had better 5-year OS compared with those who didn't (OS 66.0\% vs. 31.2\%, $p=0.033$ ). On multivariate analysis, tumor size $>5 \mathrm{~cm}$ and non-initial radiation therapy were independent risk factors for OS in all patients, non-initial radiation therapy was an independent risk factor for EFS in all patients, and tumor size $>5 \mathrm{~cm}$ was an independent risk factor for OS in patients with events.
\end{abstract}

Conclusions: Radiation therapy as a component of initial treatment can improve the OS and EFS in pediatric head and neck rhabdomyosarcoma patients by enhancing local control, and non-initial radiation therapy is an independent risk factor for OS and EFS. Salvage radiation therapy still can improve OS in patients with disease progression and relapse. Tumor size $>5 \mathrm{~cm}$ is an independent risk factor for OS in pediatric HNRMS patients with or without disease progression/relapse.

Keywords: Rhabdomyosarcoma, Pediatric, Radiation therapy, Prognosis, Head and neck, Tumor size

* Correspondence: huangdongshengtr@163.com

Pediatric Department of Beijing Tongren Hospital, Capital Medical University,

100730, 1\# Dong Jiao Min Xiang, Dongcheng District, Beijing, China

C The Author(s). 2020 Open Access This article is licensed under a Creative Commons Attribution 4.0 International License, which permits use, sharing, adaptation, distribution and reproduction in any medium or format, as long as you give appropriate credit to the original author(s) and the source, provide a link to the Creative Commons licence, and indicate if changes were made. The images or other third party material in this article are included in the article's Creative Commons licence, unless indicated otherwise in a credit line to the material. If material is not included in the article's Creative Commons licence and your intended use is not permitted by statutory regulation or exceeds the permitted use, you will need to obtain permission directly from the copyright holder. To view a copy of this licence, visit http://creativecommons.org/licenses/by/4.0/. The Creative Commons Public Domain Dedication waiver (http://creativecommons.org/publicdomain/zero/1.0/) applies to the data made available in this article, unless otherwise stated in a credit line to the data. 


\section{Background}

Rhabdomyosarcoma (RMS) is the most common childhood soft tissue sarcoma, accounting for about $50 \%$ of all patients $[1,2]$. It comprises about $4.5 \%$ of all childhood cancer with an annual incidence of 4.5 cases per 1 million children and young adults aged under 20 years $[3,4]$. This aggressive malignant tumor can develop in any part of the body, and is thought to have a primitive mesenchymal cell origin, with a propensity for striated muscle differentiation [3-5]. The treatment of RMS is a multimodal strategy, referring to the combination of chemotherapy, surgery, and radiation therapy ( $\mathrm{RT})$, as well as recent biologically targeted agents $[2,3,6]$. Over the last 3 decades the survival of RMS patients has improved substantially with 5-year OS exceeding 70\% [2, 3]. But the prognosis of relapsed and metastatic patients remained poor with 5-year OS about 30\% [2, 3, 6]. The prognosis of all RMS is strongly determined by the ability of achieving local control (control of the primary tumor site) [2,7]. The main pattern of treatment failure including disease progression and relapse is local failure, and maintaining local control is of crucial importance throughout the treatment plan [7, 8]. The two major modalities of local control are surgery and RT, which could be used separately or combined [2, 9].

Head and neck is the most common region of presentation, comprising $40 \%$ of all RMS [10, 11]. The primary sites of head and neck rhabdomyosarcoma (HNRMS) include orbit, parameningeal and nonparameningeal nonorbit head and neck. About 50\% of HNRMS cases are parameningeal type (unfavorable site), arising in the middle ear/mastoid, nasopharynx/ nasal cavity, paranasal sinus, parapharyngeal region, or pterygopalatine/infratemporal fossa [10, 11]. Local control is a significant challenge for HNRMS, especially for parameningeal type [12, 13]. Considering the complicated anatomy of this region, radical surgery would usually cause severe functional and/or cosmetic sequelae, and in most patients there would be gross residual or only a biopsy could be performed [11]. Under this circumstance RT becomes the only appropriate local control method before a second look or delayed primary excision [14].

We found in some of our pediatric HNRMS patients RT was not included as a component of the treatment plan, which was mainly attributed to parental refusal due to different personal considerations. This provided us with the possibility to compare the prognosis of these patients with others. Based on the above we tried to analyze whether RT could improve the survival in pediatric HNRMS patients, and to add evidence to it.

\section{Methods}

\section{Study design}

This is a historical observational cohort study, based on all HNRMS patients diagnosed and treated in our pediatric department from June 1st, 2013 to June 30th, 2019.

\section{Diagnostic evaluation and risk stratification}

The pretreatment diagnostic workup options included head and neck computed tomography (CT) scan and/or magnetic resonance imaging (MRI) with contrast, positron emission tomography-computed tomography (PETCT) scan, chest CT, radionuclide bone scan, bone marrow aspirates and/or trephine biopsies, cerebrospinal fluid (CSF) test (parameningeal patients). The site, size (widest dimension) and invasiveness of the primary tumor, regional nodal involvement, and metastatic status were determined. Stage was assigned according to the pretreatment staging system of Soft Tissue Sarcoma Committee of Children's Oncology Group (COG) [15]. (Table 1).

Surgical plan was determined based on pretreatment workup results. Excision was attempted on condition of no severe functional and/or cosmetic consequences. Otherwise only biopsy was done. Group was assigned according to intergroup rhabdomyosarcoma study (IRS) surgical-pathologic group system [15]. (Table 2) Pathologic subtype was classified according to the fourth edition of the World Health Organization classification of tumors of soft tissue and bone, which comprise 4 subtypes including embryonal, alveolar, spindle cell/sclerosing and pleomorphic (only seen in adults) subtypes [16].

At last the risk group was assigned with comprehensive consideration of stage, group, and pathologic subtype results, according to the risk group classification of Soft Tissue Sarcoma Committee of Children's Oncology Group [15]. (Table 3) And chemotherapy was generally guided by the risk group classification.

Table 1 TNM pretreatment staging system

\begin{tabular}{llllll}
\hline Stage & Site $^{\mathrm{a}}$ & $\mathrm{T}^{\mathrm{b}}$ & Size & $\mathrm{N}^{\mathrm{c}}$ & $\mathrm{M}^{\mathrm{d}}$ \\
\hline 1 & Nonparameningeal & T1 or T2 & Any & Any & $\mathrm{M0}$ \\
2 & Parameningeal & T1 or T2 & $\leq 5 \mathrm{~cm}$ & $\mathrm{~N} 0$ or $\mathrm{Nx}$ & $\mathrm{M} 0$ \\
3 & Parameningeal & T1 or T2 & $\leq 5 \mathrm{~cm}$ & $\mathrm{N1}$ & $\mathrm{M} 0$ \\
& & & $>5 \mathrm{~cm}$ & Any & $\mathrm{M} 0$ \\
4 & Any & T1 or T2 & Any & Any & $\mathrm{M} 1$
\end{tabular}

a. For HNRMS favorable site refers to nonparameningeal site (orbit and nonorbit nonparameningeal head and neck); unfavorable site refers to parameningeal site

b. T1, confined to primary site; $T 2$, surrounding tissue invasion c. Regional nodes N0, not involved; N1, involved; Nx, status unknown d. M0, no distant metastasis; M1 distant metastasis (includes positive cytology in CSF, pleural, or peritoneal fluid) 
Table 2 IRS surgical-pathologic group system

\begin{tabular}{|c|c|}
\hline Group & Definition \\
\hline I & Localized disease, completely resected \\
\hline$\|$ & Total gross resection, with evidence of regional spread \\
\hline A & Grossly resected tumor with microscopic residual disease \\
\hline B & $\begin{array}{l}\text { Involved regional nodes completely resected with no } \\
\text { microscopic residual disease }\end{array}$ \\
\hline C & $\begin{array}{l}\text { Involved regional nodes grossly resected with evidence of } \\
\text { microscopic residual disease }\end{array}$ \\
\hline III & Biopsy only or incomplete resection with gross residual disease \\
\hline IV & $\begin{array}{l}\text { Distant metastatic disease (excludes regional nodes and } \\
\text { adjacent organ infiltration) }\end{array}$ \\
\hline
\end{tabular}

\section{Treatment protocol}

The chemotherapy we used for low risk group patients was COG D9602 subgroup B VAC (vincristine, dactinomycin, cyclophosphamide) regimen [17]. For intermediate risk group patients, the COG D9803 standard VAC regimen was used [18]. For high risk group patients, as well as patients with disease progression or disease relapse, based on the standard VAC regimen, an optional combination with anthracyclines, platinum drugs, etoposide or irinotecan was frequently used.

RT was recommended to all patients except for Group I embryonal patients. Generally, according to the recommendation of Soft Tissue Sarcoma Committee of Children's Oncology Group, the RT dose was 36Gy for Group I alveolar patients, 36Gy or 41.4Gy for Group II patients according to nodal involvement status, 45Gy for Group III orbit patients, and 50.4Gy for other Group III patients. Group IV patients were irradiated as for other groups, including metastatic sites if possible. RT is initiated within 12 weeks after chemotherapy, and radiosensitizing agents were omitted during RT.

Second-look surgery, delayed primary excision, or salvage excision was considered only if no severe functional and/or cosmetic consequences were anticipated.

\section{Follow up}

All patients were closely followed up since diagnosis. Clinical data during and after treatment were recorded. Frequency of off-therapy surveillance was every 3 months for the first year, every 4 months for the second and third year, and once a year for the fourth and fifth

Table 3 COG risk group classification

\begin{tabular}{llll}
\hline Risk Group & Histology & Stage & Group \\
\hline Low & Embryonal & 1 & I, II, III \\
& Embryonal & 2,3 & I, II \\
Intermediate & Embryonal & 2,3 & III \\
& Alveolar & $1,2,3$ & I, II, III \\
High & Embryonal or Alveolar & 4 & IV \\
\hline
\end{tabular}

year [8]. Clinical physical examination, blood routine and biochemical tests, head and neck CT or MRI with or without contrast, and chest CT or chest X-ray were required for surveillance, and PET-CT was optional to replace all imaging examinations.

Overall survival (OS) was defined as survival from diagnosis to death of any cause. Disease progression (PD) was defined as primary tumor enlargement, and/or new lesions, and/or metastasis during primary treatment course. Disease relapse (RD) was defined as recurrence of RMS in any form after last treatment. Event free survival (EFS) was defined as survival from diagnosis to the first event of $\mathrm{PD}, \mathrm{RD}$, second tumor or death of any cause $[7,19,20]$. In this study only the first PD and RD were discussed and analyzed. The patterns of PD and RD included local (primary site), regional (regional lymph node), metastatic, and any combinations.

\section{Grouping and statistical methods}

According to whether RT was included as a component of initial treatment plan, patients were divided into initial RT group (Group IRT) and non-initial RT group (Group NIRT). According to whether RT was included as a component of salvage treatment plan, patients with events, including all PD and RD patients, were divided into salvage RT group (Group SRT) and non-salvage RT group (Group NSRT).

OS and EFS as time-to-event distributions were estimated with Kaplan-Meier method, and survival rates were estimated. Univariate analysis was performed with $\log$ rank test to detect differences between groups and Bonferroni adjustment was used to control type I error if more than two groups were compared. Multivariate analysis was performed using Cox proportional hazard model to explore risk factors and adjust confounding factors, and hazard ratios (HR) with 95\% confidence intervals (CIs) were calculated. Categorical variables were compared using chisquared test or Fisher's exact test between groups. A $p$ value $<0.05$ was considered statistically significant. Data were analyzed with IBM SPSS Statistics 26.0.

\section{Results \\ Patients' clinical characteristics}

From June 1st, 2013 to June 30th, 2019, 56 pediatric patients were admitted into our pediatric department, who were diagnosed as HNRMS with pathological confirmation. These patients formed our cohort and were diagnosed, stratified, treated and followed up by uniform protocol. The median follow up time was 31.8 (range 3.5-74.6) months for all patients, 37.6 (range 6.1-74.6) months for Group IRT, 20.6 (range 3.5-71.6) months for Group NIRT, 35.7 (range 6.1-74.6) months for Group SRT, and 20.9 (range 4.8-58.4) months for Group NSRT. The specific clinical characteristics of all 
patients and patients of different groups are showed in Table 4.

\section{Patients' survival results}

There were 26 events observed during follow up, including 14 disease progressions and 12 disease relapses. The pattern of events is showed in Table 5, and the vast majority of events $(24 / 26)$ belonged to local events (21 local and 3 local+metastatic).

The estimated 5-year OS of all patients was $69.9 \%$, and 5-year EFS was $48.8 \%$. (Fig. 1a\&c) The estimated 5-year OS of low and intermediate risk group was 88.9 and $79.8 \%$, and the 3 -year OS for high group was $22.2 \%$, which were statistically different when compared by $\log$ rank test $(p=0.002)$. (Fig. 1b) A further pairwise comparison between the 3 risk groups were done with Bonferroni adjustment, and the results showed statistical survival differences between low and high risk groups $(p=0.005)$, as well as intermediate and high risk groups $(\mathrm{p}=0.002)$, but no difference between low and intermediate groups $(p=0.345)$. The estimated 5 -year OS for the 26 patients with events (disease progression and relapse) was $41.4 \%$. (Fig. 1d).

\section{Univariate analysis of risk factors for survival}

The previously reported risk factors for survival $[15,19$, 21] were compared between groups by univariate analysis with Kaplan-Meier method and log rank test. The results are showed in Table 6. In all patients, the statistically significant risk factors of 5-year OS include tumor size, primary tumor invasiveness, metastasis, surgicalpathologic group, and initial RT; factors of 5-year EFS include tumor size and initial RT. In patients with events (disease progression and relapse), the statistically significant risk factors of 3-year OS include tumor size, primary tumor invasiveness, metastasis, surgical-pathologic group, and salvage RT.

By univariate analysis we noticed that patients treated with initial RT had better OS and EFS than those without. And in patients with events those treated with salvage $R T$ had better OS, but the influence of initial RT showed no statistical significance in these patients. (Fig. 2.)

\section{Multivariate analysis of risk factors for survival}

Cox proportional hazard model was used for multivariate analysis, and all statistically significant variables were included in the model, in order to adjust confounding factors. And considering the collinearity between variable metastasis and variable surgical-pathologic group (patients with metastasis belongs to surgical-pathologic group IV, which means there is an information overlap, and the two variables should not be in the Cox model at the same time), which was confirmed by collinearity diagnostics with condition index 19.33,variance proportion of metastasis 0.69 and surgical-pathologic group 0.93 , variable metastasis was excluded from the model. The results were expressed as HR with 95\% CIs for each variable, and a variable with $p$ value $<0.05$ was considered to be an independent prognostic factor. The multivariable analysis results are showed in Table 7 . Tumor size $>5 \mathrm{~cm}$ and non-initial RT were independent risk factors for OS in all patients, non-initial RT was an independent risk factor for EFS in all patients, and tumor size $>5 \mathrm{~cm}$ was an independent risk factor for OS in patients with events.

\section{Discussion}

Most of our HNRMS patients belonged to parameningeal type/unfavorable site (57.1\%), Group III/gross residual $(73.2 \%)$ and intermediate risk group (67.9\%). These distribution features were consistent with current published results [22]. Thus, the local control would be more dependent on RT because of the limited chances for a complete primary resection considering the complicated anatomy and functional/ cosmetic consequences [11, 14]. Baseline characteristics (Table 4.) of Group IRT and Group NIRT, as well as Group SRT and Group NSRT were generally comparable, which provided the foundation for further comparisons between groups.

In our cohort during the follow up there were 26 events, of which 24 were local events. This result was consisted with other reports, that the most common treatment failure (including disease progression and relapse) was local failure, and maintaining local control would benefit prognosis substantially $[7,8,22]$.

The COG risk group classification is an effective risk stratification strategy, which can evaluate patients' risk factors comprehensively, guide chemotherapy choice, and predict outcome $[2,3,15]$. Our survival results supported the effectiveness of this risk group classification in predicting outcome, but a pairwise comparison of survival between low and intermediate risk group didn't reach statistical significance $(p=0.345)$. This may be explained by RT as a confounding factor undermining the survival difference between the two groups, or our limited sample size to detect it. Though we couldn't prove either of them based on our current cohort, we still can see the trend of survival difference on the Kaplan Meier survival curve (Fig. 1b).

In univariate analysis process we tested some widely accepted prognostic factors in our cohort, and some reached statistical significance. Besides RT, which will be discussed later, we found that statistically significant prognostic factors for OS in all patients and patients with events were very consistent, including tumor size, primary tumor invasiveness, metastasis, and surgicalpathologic group. And besides RT, tumor size is the only 
Table 4 Clinical characteristics of all patients and patients of different groups

\begin{tabular}{|c|c|c|c|c|c|c|c|}
\hline & & All $p$ & & & Patie & vents & \\
\hline & $\begin{array}{l}\text { patients } \\
\text { n (\%) }\end{array}$ & $\begin{array}{l}\text { IRT } \\
n\end{array}$ & $\begin{array}{l}\text { NIRT } \\
n\end{array}$ & $p$ & $\begin{array}{l}\text { SRT } \\
\mathrm{n}\end{array}$ & $\begin{array}{l}\text { NSRT } \\
n\end{array}$ & $p$ \\
\hline Total cases & $56(100 \%)$ & 34 & 22 & - & 15 & 11 & - \\
\hline Gender & & & & & & & \\
\hline Male & $31(55.4 \%)$ & 22 & 9 & & 6 & 5 & \\
\hline Female & $25(44.6 \%)$ & 12 & 13 & 0.080 & 9 & 6 & $1.000 \#$ \\
\hline Age at diagnosis & & & & & & & \\
\hline$\leq 1$ y or $\geq 10$ ys & $17(30.4 \%)$ & 10 & 7 & & 4 & 4 & \\
\hline$>1-9$ ys & $39(69.6 \%)$ & 24 & 15 & 0.848 & 11 & 7 & 0.683\# \\
\hline Site of origin & & & & & & & \\
\hline Orbit & $22(39.3 \%)$ & 14 & 8 & & 9 & 1 & \\
\hline Parameningeal & $32(57.1 \%)$ & 19 & 13 & & 4 & 10 & \\
\hline Other head \& neck & $2(3.6 \%)$ & 1 & 1 & $0.813^{*}$ & 2 & 0 & $0.002 * \#$ \\
\hline Tumor size & & & & & & & \\
\hline$\leq 5 \mathrm{~cm}$ & $37(66.1 \%)$ & 25 & 12 & & 11 & 4 & \\
\hline$>5 \mathrm{~cm}$ & 19 (33.9\%) & 9 & 10 & 0.143 & 4 & 7 & $0.109 \#$ \\
\hline Histologic subtype & & & & & & & \\
\hline Embryonal & $27(48.2 \%)$ & 16 & 11 & & 6 & 5 & \\
\hline Alveolar & $29(51.8 \%)$ & 18 & 11 & 0.830 & 9 & 6 & $1.000 \#$ \\
\hline Primary tumor invasive & & & & & & & \\
\hline $\mathrm{T} 1$ & $20(35.7 \%)$ & 12 & 8 & & 7 & 2 & \\
\hline $\mathrm{T} 2$ & $36(64.3 \%)$ & 22 & 14 & 0.935 & 8 & 9 & $0.217 \#$ \\
\hline Regional nodal involve & & & & & & & \\
\hline No & $30(53.6 \%)$ & 21 & 9 & & 9 & 4 & \\
\hline N1 & $26(46.4 \%)$ & 13 & 12 & 0.126 & 6 & 7 & $0.428 \#$ \\
\hline Metastasis & & & & & & & \\
\hline MO & 49 (87.5\%) & 32 & 17 & & 13 & 9 & \\
\hline M1 & $7(12.5 \%)$ & 2 & 5 & 0.099\# & 2 & 2 & $1.000 \#$ \\
\hline TNM pretreatment stag & & & & & & & \\
\hline Stage 1 & $24(42.9 \%)$ & 15 & 9 & & 11 & 1 & \\
\hline Stage 2 & $7(12.5 \%)$ & 5 & 2 & & 0 & 2 & \\
\hline Stage 3 & $18(32.1 \%)$ & 12 & 6 & & 2 & 6 & \\
\hline Stage 4 & $7(12.5 \%)$ & 2 & 5 & NA & 2 & 2 & NA \\
\hline Surgical-pathologic grc & & & & & & & \\
\hline Group I & $0(0 \%)$ & 0 & 0 & & 0 & 0 & \\
\hline Group II & $8(14.3 \%)$ & 5 & 3 & & 3 & 0 & \\
\hline Group III & $41(73.2 \%)$ & 27 & 14 & & 10 & 9 & \\
\hline Group IV & $7(12.5 \%)$ & 2 & 5 & NA & 2 & 2 & NA \\
\hline Risk group & & & & & & & \\
\hline Low risk & $11(19.6 \%)$ & 6 & 5 & & 5 & 1 & \\
\hline Intermediate risk & 38 (67.9\%) & 26 & 12 & & 8 & 8 & \\
\hline High risk & 7 (12.5\%) & 2 & 5 & NA & 2 & 2 & NA \\
\hline
\end{tabular}

IRT: initial RT; NIRT: non-initial RT; SRT: salvage RT; NSRT: non-salvage RT.

*: Tested between parameningeal and nonparameningeal (orbit+other head \& neck) groups

NA: not tested because of limited sample size 
Table 5 Pattern of events (disease progression and relapse).*

\begin{tabular}{llll}
\hline & Disease Progression $(\mathrm{n})$ & Disease Relapse $(\mathrm{n})$ & Total \\
\hline Local & 12 & 9 & 21 \\
Regional & 0 & 1 & 1 \\
Metastatic & 0 & 1 & 1 \\
Local+Metastatic & 2 & 1 & 3 \\
Total & 14 & 12 & 26 \\
\hline
\end{tabular}

*Only first progression and first relapse were analyzed

statistically significant prognostic factor for EFS. Tumor size is an important prognostic factor for survival in HNRMS, patients with smaller tumor $(\leq 5 \mathrm{~cm})$ have better survival compared with patients with larger tumor $(>5 \mathrm{~cm})$ [7, 23]. Tumor size $>5 \mathrm{~cm}$ has been widely reported as a risk factor for survival especially in refractory patients (patients with disease progression) and recurrent patients (patients with disease relapse) [24-27]. These results are consistent with our result that tumor size could predict OS in patients with or without events. And tumor size was the strongest predictor of local failure [28], which is consistent with our results that tumor size could predict EFS over other factors.

Our univariate analysis results showed that initial RT was a statistical prognostic factor for both OS and EFS in all patients, but it was not for OS in patients with events. This might indicate that initial RT could help to improve OS by enhancing local control/ preventing local events, but once events occurred, initial RT would become a low-weight prognostic factor. We speculated that after events, salvage RT took the place of initial RT and became a high-weight prognostic factor, and this speculation was supported by our results that salvage RT was a statistically significant prognostic factor for OS in patients with events. It's reported that adequate local therapy is an important factor for survival after relapse [29], RT can further improve OS in relapsed patients undergone a repeat surgery [30], and local treatment such as RT and repeat surgery should be systemically considered even in previously irradiated patients [31]. The cure of parameningeal RMS is unlikely without RT [11]. In conclusion, our results showed that whether as a

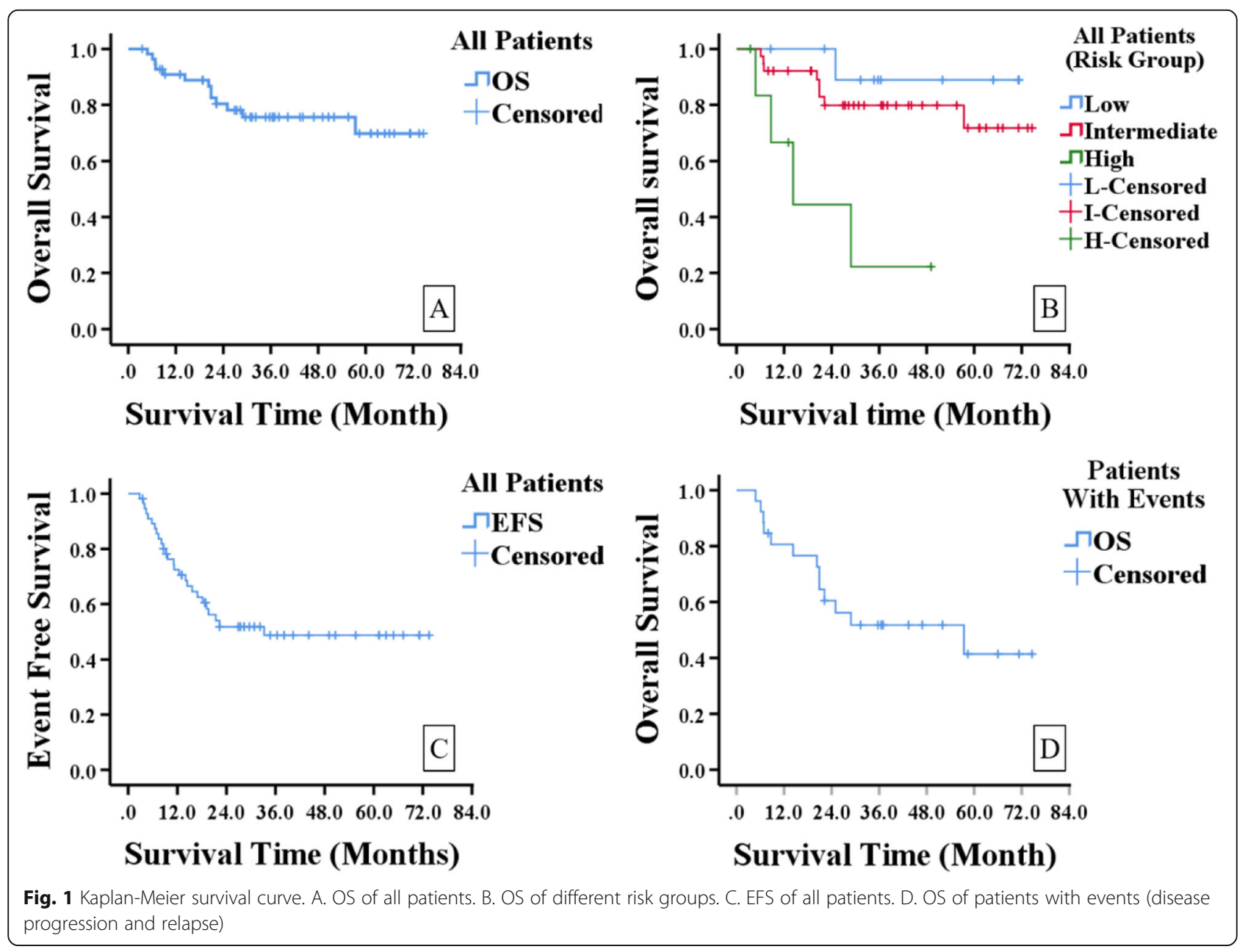


Table 6 Univariate analysis of prognostic factors for survival

\begin{tabular}{|c|c|c|c|c|c|c|}
\hline \multirow[t]{2}{*}{ Risk Factors } & \multicolumn{4}{|l|}{ All Patients } & \multicolumn{2}{|c|}{ Patients with events } \\
\hline & $5-y$ OS & $\mathrm{p}$ & $5-y$ EFS & $\mathrm{p}$ & $3-y$ OS & $p$ \\
\hline \multicolumn{7}{|l|}{ Age at diagnosis } \\
\hline$\leq 1$ y or $\geq 10$ ys & $80.9 \%$ & & $49.6 \%$ & & $60.0 \%$ & \\
\hline$>1-9$ ys & $66.1 \%$ & 0.617 & $48.4 \%$ & 0.809 & $48.9 \%$ & 0.633 \\
\hline \multicolumn{7}{|l|}{ Site of origin } \\
\hline Parameningeal & $56.6 \%$ & & $49.0 \%$ & & 39.3 & \\
\hline Non-Parameningeal & $81.9 \%$ & 0.204 & $46.6 \%$ & 0.903 & 65.6 & 0.094 \\
\hline \multicolumn{7}{|l|}{ Tumor size } \\
\hline$\leq 5 \mathrm{~cm}$ & $83.5 \%$ & & $56.0 \%$ & & $79.4 \%$ & \\
\hline$>5 \mathrm{~cm}$ & $40.3 \%$ & $<0.001$ & $30.1 \%$ & $0.035^{*}$ & $10.4 \%$ & $<0.001$ \\
\hline \multicolumn{7}{|l|}{ Histologic subtype } \\
\hline Embryonal & $74.6 \%$ & & $51.8 \%$ & & $\begin{array}{l}35.8 \% \\
\text { (5-y OS) }\end{array}$ & \\
\hline Alveolar & $65.5 \%$ & 0.172 & $46.9 \%$ & 0.339 & $\begin{array}{l}36.4 \% \\
\text { (5-y OS) }\end{array}$ & 0.203 \\
\hline \multicolumn{7}{|c|}{ Primary tumor invasiveness } \\
\hline $\mathrm{T} 1$ & $95 \%$ & & $49.5 \%$ & & $88.9 \%$ & \\
\hline $\mathrm{T} 2$ & $51.4 \%$ & 0.013 & $50.0 \%$ & 0.583 & $29.6 \%$ & 0.006 \\
\hline \multicolumn{7}{|c|}{ Regional nodal involvement } \\
\hline NO & $73.6 \%$ & & $51.4 \%$ & & $60.6 \%$ & \\
\hline $\mathrm{N} 1$ & $67.8 \%$ & 0.330 & $40.8 \%$ & 0.498 & $42.3 \%$ & 0.481 \\
\hline \multicolumn{7}{|l|}{ Metastasis } \\
\hline MO & $75.7 \%$ & & $51.2 \%$ & & $62.0 \%$ & \\
\hline M1 & $22.2 \%$ (3-y OS) & $<0.001$ & $25.0 \%$ (15-m EFS) & 0.097 & $0.0 \%$ & 0.005 \\
\hline \multicolumn{7}{|c|}{ Surgical-pathologic group } \\
\hline Group II & $100 \%$ & & $62.5 \%$ & & $100 \%$ & \\
\hline Group III & $66.8 \%$ & & $48.3 \%$ & & $55.6 \%$ & \\
\hline Group IV & $22.2 \%$ (3-y OS) & $0.001 \#$ & $25.0 \%$ (15-m EFS) & 0.198 & $0.0 \%$ & $0.007 \#$ \\
\hline \multicolumn{7}{|l|}{ Initial RT } \\
\hline Yes & $80.3 \%$ & & $63.9 \%$ & & $35.8 \%$ & \\
\hline No & $49.7 \%$ & 0.003 & $\begin{array}{l}21.9 \% \\
(20-m \text { EFS) }\end{array}$ & $<0.001$ & $36.4 \%$ & 0.178 \\
\hline \multicolumn{7}{|l|}{ Salvage RT } \\
\hline Yes & - & & - & & $66.0 \%$ & \\
\hline No & - & - & - & - & $31.2 \%$ & 0.033 \\
\hline
\end{tabular}

\# Pairwise comparison (Bonferroni adjustment: $p<0.0167$ is considered statistically significant)

5-year OS of all patients: Group II vs Group III ( $(p=0.098)$, Group II vs Group IV $(p=0.003)$, Group III vs Group IV $(p=0.003)$

3-year OS of patients with events (disease progress and relapse): Group II vs Group III ( $p=0.127)$, Group II vs Group IV ( $p=0.018)$, Group III vs Group IV ( $p=0.014$ )

* Breslow test results

component of initial or salvage treatment plan, RT could improve patients' OS.

In order to adjust confounding factors, further multivariate analyses were performed using Cox proportional hazard model. First, tumor size was proved to be an independent prognostic factor for OS in patients with or without events, which confirmed its important influence on patients' outcome. Second, initial RT was proved to be an independent prognostic factor for OS and EFS, which confirmed it as a very important modality to improve OS by enhancing local control. Third, salvage RT was not an independent prognostic factor for OS in patients with events. In our cohort patients with events (disease progression and relapse) generally refers to refractory and recurrent patients. These patients' survival is affected by many factors and some of them may be 


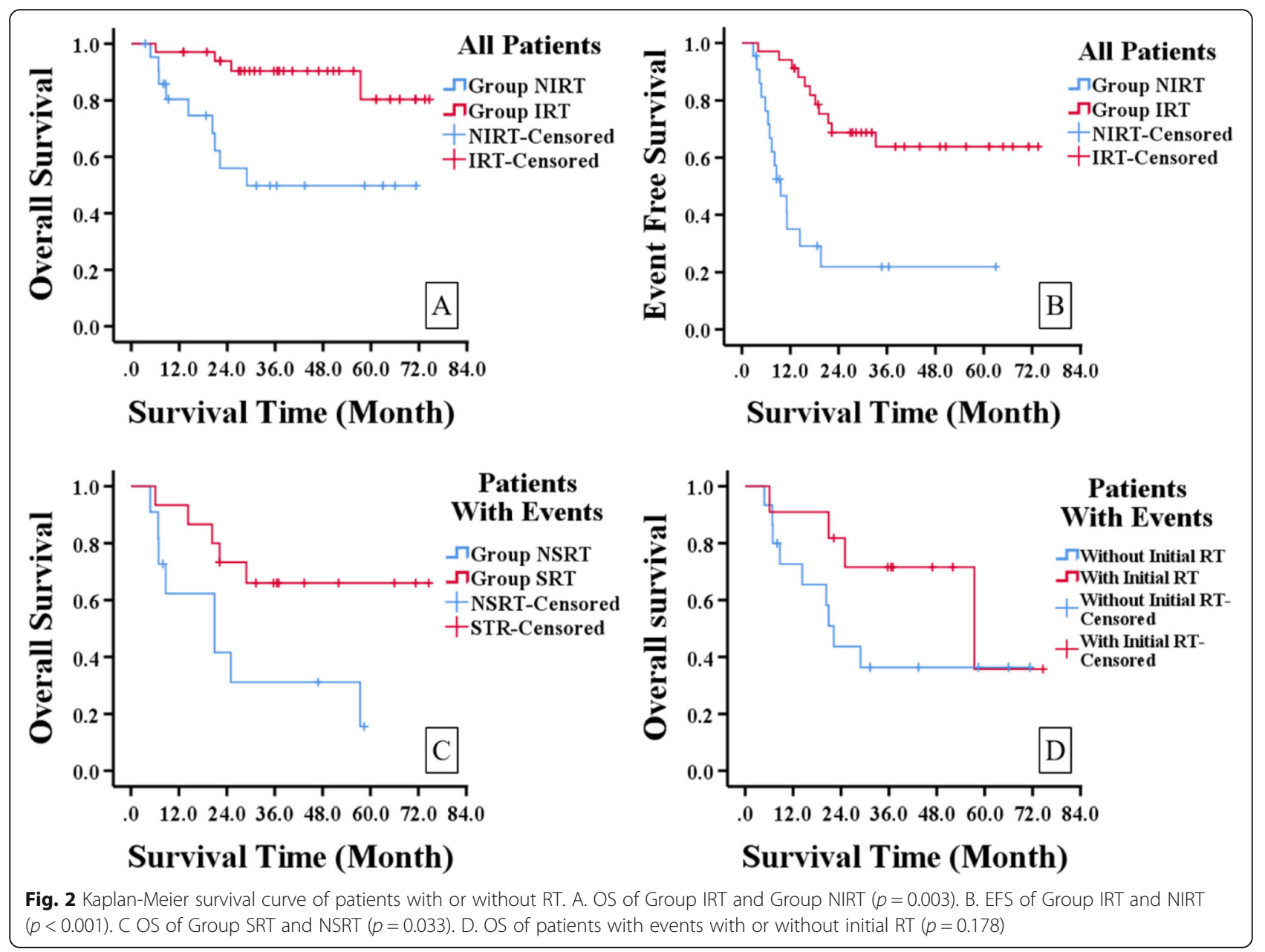

higher-weight prognostic factors, such as tumor size, primary site, regional nodal involvement, metastasis, repeat surgery, previous chemo and RT plan, multi-relapse, etc. $[3,19,27,29,32]$. All these factors make salvage RT unlikely to be an independent prognostic factor.

Over the last 3 decades with the continuous efforts made by large cooperative groups, such as the COG Soft Tissue Sarcoma Committee in North America, the European pediatrics Soft Tissue Sarcoma Study Group (EpSSG), etc., the current 5-year OS for pediatric RMS patients exceeds $70 \%$ [2, 3]. For patients with poor prognosis, treatment failure is mainly due to local failure, which refers to primary tumor progression or recurrence, including the combination of local failure with regional nodal failure, and/or metastasis. The key to improve prognosis is to maintain local control. The first thing to cure RMS is the eradication of the primary tumor, which is realized by surgery and/or RT, then at the same time chemotherapy can eradicate micro residual or disseminated tumor cells [2]. It's reported that patients without RT as a component of the treatment plan have a poor prognosis [33], and in HNRMS patients

Table 7 Multivariate analysis results of Cox proportional model

\begin{tabular}{|c|c|c|c|c|c|c|c|c|c|}
\hline \multirow[t]{2}{*}{ Risk Factors } & \multicolumn{3}{|c|}{ OS (All Patients) } & \multicolumn{3}{|c|}{ EFS (All Patients) } & \multicolumn{3}{|c|}{ OS (Patients with Events) } \\
\hline & $\mathrm{HR}$ & $95 \% \mathrm{Cls}$ & $\mathrm{p}$ & $\mathrm{HR}$ & $95 \% \mathrm{Cls}$ & $\mathrm{p}$ & $\mathrm{HR}$ & $95 \% \mathrm{Cls}$ & $\mathrm{p}$ \\
\hline Tumor size & 5.06 & $1.17-21.93$ & 0.030 & 1.92 & $0.86-4.27$ & 0.110 & 5.61 & $1.12-28.06$ & 0.036 \\
\hline Primary tumor invasiveness & 4.59 & $0.51-41.13$ & 0.173 & - & - & - & 5.96 & $0.62-54.59$ & 0.114 \\
\hline Surgical-pathologic group & 1.26 & $0.33-4.84$ & 0.741 & - & - & - & 1.50 & $0.31-7.40$ & 0.617 \\
\hline Initial RT & 4.66 & $1.33-16.36$ & 0.016 & 4.69 & $2.08-10.55$ & $<0.001$ & - & - & - \\
\hline Salvage RT & - & - & - & - & - & - & 2.06 & $0.54-7.79$ & 0.289 \\
\hline
\end{tabular}


if the primary tumor is unresectable, RT and chemotherapy are the mainstay of initial treatment [11]. Here we cannot overemphasize the importance of RT in treating pediatric HNRMS patients, and omitting RT may lead to poor prognosis.

Despite the benefit of RT, about $40 \%(22 / 56)$ of our patients' parents initially rejected the adoption of RT for their children, which are generally due to two reasons: one is the concern about long-term morbidity related with RT such as orbital hypoplasia, eye problems, and pituitary dysfunction, etc., the other is the fact that some kids show very good/complete response to initial chemo regiments, which enhanced parents' confidence that chemotherapy is reliable and capable of cure. Regarding the two situations, we may consider introducing them less toxic RT modalities, such as proton radiotherapy, brachytherapy, etc., as well as adequately explaining the necessity of RT, the risk of refusing it, and the limited predictive value of initial response to chemotherapy, to ease their concern and enhance their confidence for RT.

\section{Limitations}

This is a single-center historical cohort study with a small sample size, but our uniform diagnostic and therapeutic protocol could also be a strength. Our hospital is a tertiary center with domestically high-ranking ophthalmology and otorhinolaryngology head \& neck surgery department, also the fact that we didn't identify surgicalpathologic group I patients may indicate a selection bias. These factors may limit the generalizability of this study. We can't acquire the PAX-FOXO1 fusion gene status in nearly half of our alveolar patients, in order not to cause false interpretations it was not analyzed in this study. But PAX-FOXO1 fusion gene status is absolutely a very important prognostic factor and is widely reported [2, $19,20]$, not being able to analyze it could be a flaw of this study.

\section{Conclusions}

In conclusion, RT as a component of initial treatment can improve the OS and EFS in pediatric HNRMS patients by enhancing local control, and non-initial RT is an independent risk factor for OS and EFS. Salvage RT still can improve OS in patients with disease progression and relapse. Tumor size $>5 \mathrm{~cm}$ is an independent risk factor for OS in pediatric HNRMS patients with or without disease progression/relapse.

\footnotetext{
Abbreviations

OS: Overall Survival; EFS: Event Free Survival; RMS: Rhabdomyosarcoma; RT: Radiation Therapy; HNRMS: Head and Neck Rhabdomyosarcoma; CT: Computed Tomography; PET-CT: Positron Emission TomographyComputed Tomography; CSF: Cerebrospinal Fluid; COG: Children's Oncology Group; IRS: Intergroup Rhabdomyosarcoma Study; VAC: Vincristine, Dactinomycin, Cyclophosphamide.; PD: Disease Progression; RD: Disease Relapse; HR: Hazard Ratio; Cl: Confidence Interval; Group IRT: Initial Radiation
}

Therapy Group; Group NIRT: Non-initial Radiation Therapy Group; Group SRT: Salvage Radiation Therapy Group; Group NSRT: Non-salvage Radiation Therapy Group

\section{Acknowledgements \\ Not applicable.}

\section{Authors' Contubutions}

YW designed the study, collected, analyzed and interpreted all the data, and completed the manuscript writing. $\mathrm{DH}$ initiated the study and participated in designing, did the critical revision of the manuscript, and provided the funding. $W Z, Y Z, H H, J L$ contributed in clinical data accumulation and collection, and participated in study design. All authors read and approved the final manuscript.

\section{Funding}

This study was funded by the Special Fund of the Pediatric Medical Coordinated Development Center of Beijing Hospitals Authority (No. XTZD20180203), and Beijing Hospitals Authority Mission Plan (Code: DFL20180201).

\section{Availability of data and materials}

Not applicable.

\section{Ethics approval and consent to participate}

This study was conducted in accordance with the declaration of Helsinki and with approval from the Ethics Committee of Capital Medical University, Beijing Tongren Hospital. Written informed consent was obtained from all participants' guardians.

Consent for publication

Not applicable.

\section{Competing interests}

The authors declare that they have no competing interests.

Received: 25 April 2020 Accepted: 20 May 2020

Published online: 29 May 2020

\section{References}

1. Amer KM, Thomson JE, Congiusta D, Dobitsch A, Chaudhry A, Li M, Chaudhry A, Bozzo A, Siracuse B, Aytekin MN, et al. Epidemiology, incidence, and survival of Rhabdomyosarcoma subtypes: SEER and ICES database analysis. J Orthop Res. 2019:37(10):2226-30.

2. Skapek SX, Ferrari A, Gupta AA, Lupo PJ, Butler E, Shipley J, Barr FG, Hawkins DS. Rhabdomyosarcoma. Nat Rev Dis Primers. 2019:5(1):1.

3. Chen C, Dorado Garcia H, Scheer M, Henssen AG. Current and future treatment strategies for Rhabdomyosarcoma. Front Oncol. 2019:9:1458.

4. Bisogno G, De Salvo GL, Bergeron C, Gallego Melcon S, Merks JH, Kelsey A, Martelli H, Minard-Colin V, Orbach D, Glosli H, et al. Vinorelbine and continuous low-dose cyclophosphamide as maintenance chemotherapy in patients with high-risk rhabdomyosarcoma (RMS 2005): a multicentre, openlabel, randomised, phase 3 trial. Lancet Oncol. 2019:20(11):1566-75.

5. Bisogno G, Jenney M, Bergeron C, Gallego Melcon S, Ferrari A, Oberlin O, Carli M, Stevens M, Kelsey A, De Paoli A, et al. Addition of dose-intensified doxorubicin to standard chemotherapy for rhabdomyosarcoma (EpSSG RMS 2005): a multicentre, open-label, randomised controlled, phase 3 trial. Lancet Oncol. 2018;19(8):1061-71.

6. Yohe ME, Heske CM, Stewart E, Adamson PC, Ahmed N, Antonescu CR, Chen E, Collins N, Ehrlich A, Galindo RL, et al. Insights into pediatric rhabdomyosarcoma research: challenges and goals. Pediatr Blood Cancer. 2019;66(10):e27869.

7. Casey DL, Chi YY, Donaldson SS, Hawkins DS, Tian J, Arndt CA, Rodeberg DA, Routh JC, Lautz TB, Gupta AA, et al. Increased local failure for patients with intermediate-risk rhabdomyosarcoma on ARST0531: a report from the Children's oncology group. Cancer. 2019;125(18):3242-8.

8. Vaarwerk B, Mallebranche C, Affinita MC, van der Lee JH, Ferrari A, Chisholm JC, Defachelles AS, De Salvo GL, Corradini N, Minard-Colin V, et al. Is surveillance imaging in pediatric patients treated for localized rhabdomyosarcoma useful? The European experience. Cancer. 2020;126(4): 823-31. 
9. Ermoian RP, Breneman J, Walterhouse DO, Chi YY, Meza J, Anderson J, Hawkins DS, Hayes-Jordan AA, Parham DM, Yock Tl et al: 45 Gy is not sufficient radiotherapy dose for Group III orbital embryonal rhabdomyosarcoma after less than complete response to 12 weeks of ARST0331 chemotherapy: A report from the Soft Tissue Sarcoma Committee of the Children's Oncology Group. Pediatr Blood Cancer 2017, 64(9).

10. Owosho AABCD, Huang SCM, Chen SM, Kashikar SD, Estilo CLD, Wolden SLM, Wexler LHM, Huryn JMD, Antonescu CRM. A clinicopathologic study of head and neck rhabdomyosarcomas showing FOXO1 fusion-positive alveolar and MYOD1-mutant sclerosing are associated with unfavorable outcome. Oral Oncol. 2016:61:89-97.

11. Defachelles AS, Rey A, Oberlin O, Spooner D, Stevens MC. Treatment of nonmetastatic cranial parameningeal rhabdomyosarcoma in children younger than 3 years old: results from international society of pediatric oncology studies MMT 89 and 95. J Clin Oncol. 2009;27(8):1310-5.

12. Turner JH, Richmon JD. Head and neck rhabdomyosarcoma: a critical analysis of population-based incidence and survival data. Otolaryngol Head Neck Surg. 2011;145(6):967-73.

13. Yang JC, Wexler LH, Meyers PA, Wolden SL. Parameningeal rhabdomyosarcoma: outcomes and opportunities. Int J Radiat Oncol Bio Phys. 2013;85(1):e61-6.

14. Spalding AC, Hawkins DS, Donaldson SS, Anderson JR, Lyden E, Laurie F, Wolden SL, Arndt CA, Michalski JM. The effect of radiation timing on patients with high-risk features of parameningeal rhabdomyosarcoma: an analysis of IRS-IV and D9803. Int J Radiat Oncol Biol Phys. 2013;87(3): 512-6.

15. Malempati S, Hawkins DS. Rhabdomyosarcoma: review of the Children's oncology group (COG) soft-tissue sarcoma committee experience and rationale for current COG studies. Pediatr Blood Cancer. 2012;59(1):5-10.

16. Rudzinski ER, Anderson JR, Hawkins DS, Skapek SX, Parham DM, Teot LA The World Health Organization classification of skeletal muscle tumors in pediatric Rhabdomyosarcoma: a report from the Children's oncology group. Arch Pathol Lab Med. 2015;139(10):1281-7.

17. Raney RB, Walterhouse DO, Meza JL, Andrassy RJ, Breneman JC, Crist WM, Maurer HM, Meyer WH, Parham DM, Anderson JR. Results of the intergroup Rhabdomyosarcoma study group D9602 protocol, using vincristine and dactinomycin with or without cyclophosphamide and radiation therapy, for newly diagnosed patients with low-risk embryonal rhabdomyosarcoma: a report from the soft tissue sarcoma Committee of the Children's oncology group. J Clin Oncol. 2011;29(10):1312-8.

18. Arndt CA, Stoner JA, Hawkins DS, Rodeberg DA, Hayes-Jordan AA, Paidas CN, Parham DM, Teot LA, Wharam MD, Breneman JC, et al. Vincristine, actinomycin, and cyclophosphamide compared with vincristine, actinomycin, and cyclophosphamide alternating with vincristine, topotecan, and cyclophosphamide for intermediate-risk rhabdomyosarcoma: children's oncology group study D9803. J Clin Oncol. 2009;27(31):5182-8.

19. Hibbitts E, Chi YY, Hawkins DS, Barr FG, Bradley JA, Dasgupta R, Meyer WH, Rodeberg DA, Rudzinski ER, Spunt SL, et al. Refinement of risk stratification for childhood rhabdomyosarcoma using FOXO1 fusion status in addition to established clinical outcome predictors: a report from the Children's oncology group. Cancer Med. 2019;8(14):6437-48.

20. Skapek SX, Anderson J, Barr FG, Bridge JA, Gastier-Foster JM, Parham DM, Rudzinski ER, Triche T, Hawkins DS. PAX-FOXO1 fusion status drives unfavorable outcome for children with rhabdomyosarcoma: a children's oncology group report. Pediatr Blood Cancer. 2013;60(9):1411-7.

21. Gallego S, Zanetti I, Orbach D, Ranchere D, Shipley J, Zin A, Bergeron C, de Salvo GL, Chisholm J, Ferrari A, et al. Fusion status in patients with lymph node-positive (N1) alveolar rhabdomyosarcoma is a powerful predictor of prognosis: experience of the European Paediatric soft tissue sarcoma study group (EpSSG). Cancer. 2018;124(15):3201-9.

22. Lautz TB, Chi YY, Tian J, Gupta AA, Wolden SL, Routh JC, Casey DL, Dasgupta R, Hawkins DS, Rodeberg DA. Relationship between tumor response at therapy completion and prognosis in patients with group III rhabdomyosarcoma: a report from the Children's oncology group. Int J Cancer. 2020.

23. Crist W, Gehan EA, Ragab AH, Dickman PS, Donaldson SS, Fryer C, Hammond D, Hays DM, Herrmann J, Heyn R, et al. The third intergroup Rhabdomyosarcoma study. J Clin Oncol. 1995;13(3):610-30.

24. Mattke AC, Bailey EJ, Schuck A, Dantonello T, Leuschner I, Klingebiel T, Treuner J, Koscielniak E. Does the time-point of relapse influence outcome in pediatric rhabdomyosarcomas? Pediatr Blood Cancer. 2009;52(7):772-6.
25. Dantonello TM, Int-Veen C, Winkler P, Leuschner I, Schuck A, Schmidt BF, Lochbuehler H, Kirsch S, Hallmen E, Veit-Friedrich I, et al. Initial patient characteristics can predict pattern and risk of relapse in localized rhabdomyosarcoma. J Clin Oncol. 2008;26(3):406-13.

26. Mazzoleni S, Bisogno G, Garaventa A, Cecchetto G, Ferrari A, Sotti G, Donfrancesco A, Madon E, Casula L, Carli M, et al. Outcomes and prognostic factors after recurrence in children and adolescents with nonmetastatic rhabdomyosarcoma. Cancer. 2005;104(1):183-90.

27. Chisholm JC, Marandet J, Rey A, Scopinaro M, de Toledo JS, Merks JH, O'Meara A, Stevens MC, Oberlin O. Prognostic factors after relapse in nonmetastatic rhabdomyosarcoma: a nomogram to better define patients who can be salvaged with further therapy. J Clin Oncol. 2011;29(10):1319-25.

28. Wolden SL, Lyden ER, Arndt CA, Hawkins DS, Anderson JR, Rodeberg DA, Morris CD, Donaldson SS. Local control for intermediate-risk Rhabdomyosarcoma: results from D9803 according to histology, group, site, and size: a report from the Children's oncology group. Int J Radiat Oncol Biol Phys. 2015;93(5):1071-6.

29. Dantonello TM, Int-Veen C, Schuck A, Seitz G, Leuschner I, Nathrath M, Schlegel PG, Kontny U, Behnisch W, Veit-Friedrich I, et al. Survival following disease recurrence of primary localized alveolar rhabdomyosarcoma. Pediatr Blood Cancer. 2013;60(8):1267-73.

30. De Corti F, Bisogno G, Dall'Igna P, Ferrari A, Buffa P, De Paoli A, Cecchetto G. Does surgery have a role in the treatment of local relapses of nonmetastatic rhabdomyosarcoma? Pediatr Blood Cancer. 2011;57(7):1261-5.

31. Winter S, Fasola S, Brisse H, Mosseri V, Orbach D. Relapse after localized rhabdomyosarcoma: evaluation of the efficacy of second-line chemotherapy. Pediatr Blood Cancer. 2015;62(11):1935-41.

32. Oberlin O, Rey A, Lyden E, Bisogno G, Stevens MC, Meyer WH, Carli M, Anderson JR. Prognostic factors in metastatic rhabdomyosarcomas: results of a pooled analysis from United States and European cooperative groups. $J$ Clin Oncol. 2008;26(14):2384-9.

33. Merks JH, De Salvo GL, Bergeron C, Bisogno G, De Paoli A, Ferrari A, Rey A, Oberlin O, Stevens MC, Kelsey A, et al. Parameningeal rhabdomyosarcoma in pediatric age: results of a pooled analysis from north American and European cooperative groups. Ann Oncol. 2014;25(1):231-6.

\section{Publisher's Note}

Springer Nature remains neutral with regard to jurisdictional claims in published maps and institutional affiliations.

Ready to submit your research? Choose BMC and benefit from:

- fast, convenient online submission

- thorough peer review by experienced researchers in your field

- rapid publication on acceptance

- support for research data, including large and complex data types

- gold Open Access which fosters wider collaboration and increased citations

- maximum visibility for your research: over $100 \mathrm{M}$ website views per year

At $\mathrm{BMC}$, research is always in progress.

Learn more biomedcentral.com/submission 